Article

\title{
Comparison of cellobiose and glucose transformation to ethylene glycol
}

\author{
Junying Zhang a,b, Xiaofeng Yang a, Baolin Hou a, Aiqin Wang a,*, Zhenlei Li a,b, Hua Wanga, \\ Tao Zhang a,\# \\ a State Key Laboratory of Catalysis, Dalian Institute of Chemical Physics, Chinese Academy of Sciences, Dalian 116023, Liaoning, China \\ b University of Chinese Academy of Sciences, Beijing 100049, China
}

\section{A R T I C L E I N F O}

Article history:

Received 29 April 2014

Accepted 10 May 2014

Published 20 November 2014

\section{Keywords:}

Cellobiose

Reaction mechanism

Glucose

Ethylene glycol

\begin{abstract}
A B S T R A C T
Cellobiose was used as a model feedstock to probe the reaction pathways of cellulose to ethylene glycol (EG). Its reactivity was compared with that of glucose using a catalyst composed of $\mathrm{H}_{2} \mathrm{WO}_{4}$ and $\mathrm{Ru} / \mathrm{C}$. EG can be produced by both the direct retro-aldol condensation of cellobiose and the retro-aldol condensation of glucose derived from cellobiose hydrolysis. The direct retro-aldol condensation of cellobiose further promoted the hydrolysis of cellobiose. Cellobiose has a lower reactivity for retro-aldol condensation than glucose, which decreased the formation rate of glycolaldehyde and made it more matched with the subsequent hydrogenation rate, thus leading to increased yield of EG from cellobiose.
\end{abstract}

(C) 2014, Dalian Institute of Chemical Physics, Chinese Academy of Sciences. Published by Elsevier B.V. All rights reserved.

\section{Introduction}

Lignocellulose is the most abundant non-edible biomass in nature, and can be a renewable hydrocarbon source for the production of liquid fuels and chemicals, which is important for a sustainable society [1-22]. Among the various chemical transformation routes of cellulose, the one-pot catalytic transformation of cellulose and hemicellulose to ethylene glycol (EG) and propylene glycol (PG) has attracted considerable attention from both academic and industrial communities because both EG and PG are commodity chemicals widely applied in the polyester industry [22-36]. Since the first report by our group on cellulose conversion to EG [23], much progress has been made in catalyst design and mechanistic understanding both from our groups [24-31] and other groups [21,36]. The original $\mathrm{Ni}-\mathrm{W}_{2} \mathrm{C} / \mathrm{AC}$ catalyst has now been replaced by a more durable and versatile dual component catalyst composed of tungstic acid and $\mathrm{Ru} / \mathrm{C}$ [30] or Raney $\mathrm{Ni}$ [31], which resulted in the significant increase in recyclable times from less than 3 to more than 30. On the other hand, the understanding of the reaction mechanism is approaching knowledge of the nature of the active sites. In particular, the interplay between the tungstic compound and cellulose is now believed to be by homogeneous catalysis instead of heterogeneous catalysis and the selective C-C cleavage of cellulose or glucose follows a retro-aldol condensation pathway [30-35].

In spite of these advances, the elucidation of the reaction mechanism on the molecular level has not been attained yet. For example, the production of EG from cellulose is believed to involve three consecutive reactions: (1) hydrolysis of cellulose to glucose, (2) retro-aldol condensation of glucose to glycolaldehyde (GA), and (3) hydrogenation of GA to EG. However, it is

\footnotetext{
* Corresponding author. Tel: +86-411-84379348; Fax: +86-411-84685940; E-mail: aqwang@dicp.ac.cn

\# Corresponding author. Tel: +86-411-84379015; Fax: +86-411-84691570; E-mail: taozhang@dicp.ac.cn

This work was supported by the National Natural Science Foundation of China (21176235, 21373206, and 21206159).

DOI: 10.1016/S1872-2067(14)60151-0 | http://www.sciencedirect.com/science/journal/18722067 | Chin. J. Catal., Vol. 35, No. 11, November 2014
} 
known that the hydrolysis of cellulose to glucose proceeds very slowly and many soluble celloligosaccharides are formed as intermediates during the hydrolysis $[37,38]$. In this case, it will be interesting to know whether these celloligosaccharide intermediates also undergo retro-aldol condensation to produce GA as glucose does, and if they do, to what extent do these reactions contribute to the total production of EG from cellulose.

To address these questions, we made a comparative study of cellobiose and glucose conversion in the present work. Cellobiose is a glucose dimer connected with a $\beta$-1,4-glycosidic bond. It is the simplest molecule that resembles the cellulose structure [39-42]. When cellobiose is used as the feedstock, almost all the intermediates can be identified and quantified, which overcomes the difficulty in identifying the intermediates in cellulose conversion. Furthermore, cellobiose has one $\beta$-1,4-glycosidic bond and therefore all the reactions that occur on cellulose, namely, hydrolysis, $\mathrm{C}-\mathrm{C}$ bond cleavage, and hydrogenation, also occur on cellobiose. Therefore, cellobiose is an ideal probe molecule for the mechanistic study of cellulose conversion.

\section{Experimental}

In all experiments, tungstic acid $\mathrm{H}_{2} \mathrm{WO}_{4}$, Sinopharm Chemical Reagent Co., Ltd.), cellobiose (J \& K Chemical) and glucose (J $\& \mathrm{~K}$ Chemical) were used as received. Catalytic reactions of glucose and cellobiose were performed in a semi-continuous stainless steel autoclave (Parr Instrument Company, $300 \mathrm{~mL}$ ) equipped with sampling tube, stirring impeller, and temperature and pressure control systems. In a typical reaction, $0.1 \mathrm{~g}$ $\mathrm{H}_{2} \mathrm{WO}_{4}, 0.3 \mathrm{~g} \mathrm{Ru} / \mathrm{C}$, and $90 \mathrm{~mL}$ water were put into the autoclave. The autoclave was flushed with $\mathrm{H}_{2}$ for five times and then sealed. The autoclave was then heated to the desired temperature, and $10 \mathrm{~mL}$ of an aqueous solution of glucose or cellobiose at a concentration of $1.63 \mathrm{~mol}_{\text {carbon }} / \mathrm{L}$ was fed in by a Shimadzu LC pump (LC-20A) at a flow rate of $10 \mathrm{~mL} / \mathrm{min}$. It took $1 \mathrm{~min}$ to finish the feeding process. Then, pure $\mathrm{H}_{2}$ gas was charged in until a pressure of $6 \mathrm{MPa}$, and the reaction was started by strong agitation at $1000 \mathrm{r} / \mathrm{min}$, and this point was considered as the initial time $(t=0)$. Samples were taken from the reactor at fixed time intervals for analysis.

After filtration through a $0.45 \mu \mathrm{m}$ PTFE filter, the liquid samples were analyzed by a high performance liquid chromatograph (HPLC, Aglient 1200) in combination with mass spectroscopy (MS), with water as the mobile phase and RI as the detector. For the separation of polyols, a Shodex SC100 column was used with a water flow rate of $0.6 \mathrm{~mL} / \mathrm{min}$ and column temperature of $348 \mathrm{~K}$. For the separation of unsaturated intermediates, a CARBOSep CHO-620 column was used with a water flow rate of $0.4 \mathrm{~mL} / \mathrm{min}$ and column temperature of $348 \mathrm{~K}$. The qualitative analysis of the intermediates and products was made by HPLC-MS. The quantitative analysis was by an external standard method. The yields of intermediates and products were calculated as: yield $(\%)=$ (mass of intermediates or products) $/$ (mass of sugar put into the reactor) $\times 100 \%$.

The Gibbs free energy of the reactions was calculated with a full electron density functional theory (DFT) calculation by the program package $\mathrm{DMol}^{3}$ in the Materials Studio of Accelrys Inc. $[43,44]$. Localized double-numerical basis sets with polarization functions (DNP) were used, which are more accurate than but comparable in size to the Gaussian basis sets $6-31 G^{* *}$. The non-local exchange-correlation functional of BLYP was employed. The convergences of energy and gradient used $1 \times 10^{-5}$ hartree and $2 \times 10^{-3}$ hartree/Å, respectively.

\section{Results and discussion}

\subsection{Reaction pathway}

To understand the reaction pathways for the conversion of cellobiose to ethylene glycol, liquid samples were taken from the reactor at fixed time intervals for analysis. Fig. 1 presents the typical HPLC chromatograph of the liquid products from cellobiose conversion catalyzed by $\mathrm{H}_{2} \mathrm{WO}_{4}$ and $\mathrm{Ru} / \mathrm{C}$ at $453 \mathrm{~K}$ for $20 \mathrm{~min}$. At least 15 compounds were present in the process of cellobiose conversion and of these, 14 compounds were identified. Among these, glucosyl-erythrose (GE) and glucosyl-erythritol (GER) were particularly interesting because they came from the direct $\mathrm{C}-\mathrm{C}$ bond cleavage of cellobiose and not glucose by a retro-aldol reaction pathway. The formation of GE in cellobiose conversion was also observed by Arai group under sub- and super-critical water conditions [39,40]. The formation of GER resulted from the hydrogenation of GE over $\mathrm{Ru} / \mathrm{C}$, similarly to the formation of 3- $\beta$-D-glucopyranosylD-glucitol from cellobiose hydrogenation $[41,42]$. In addition to the $\mathrm{C} 10$ and C12 sugar and sugar alcohols, there were also C2-C6 sugars (GA, glucose, mannose, and fructose), sugar alcohols (sorbitol, mannitol, and erythritol), and polyols (EG, hydroxyacetone). In cellulose conversion to EG, most workers believe that cellulose is first hydrolyzed to glucose and the resultant glucose undergoes retro-aldol condensation to produce GA. However, in the present work, the detection of GE and GER unequivocally indicated that GA can also be produced directly from the retro-aldol condensation of cellobiose. By extrapolating this result to cellulose conversion, we concluded that glu-

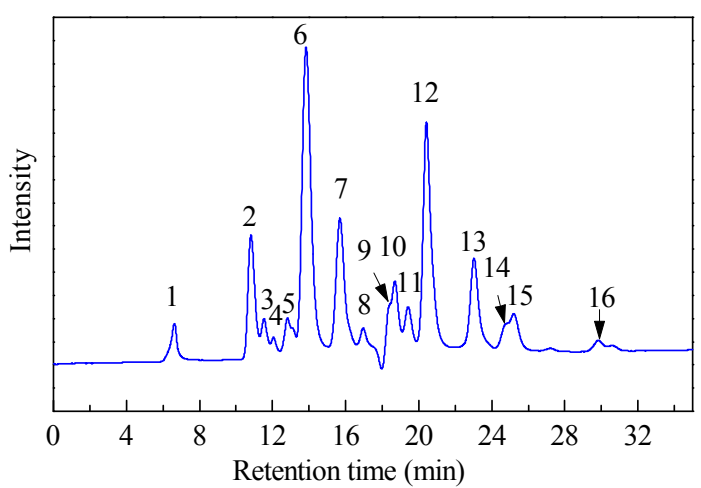

Fig. 1. Typical HPLC analysis for the products of cellobiose conversion catalyzed by $\mathrm{H}_{2} \mathrm{WO}_{4}$ and $\mathrm{Ru} / \mathrm{C}$. Reaction conditions: $0.10 \mathrm{~g} \mathrm{H}_{2} \mathrm{WO}_{4}$, $0.30 \mathrm{~g} \mathrm{Ru} / \mathrm{AC}, 453 \mathrm{~K}, 6 \mathrm{MPa} \mathrm{H}$, $20 \mathrm{~min}, 1000 \mathrm{r} / \mathrm{min}$. 1-Acids; 2-Cellobiose; 3-Glucosyl-erythrose; 4-Glucosyl-erythritol; 5-Glucopyranosyl-D-glucitol; 6-Glucose; 7-Mannose; 8-Fructose; 9-Erythritol; 10-Glycolaldehyde; 11-Mannitol; 12-Ethylene glycol; 13-Sorbitol; 14-Hydroxyacetone; 15-Unknown. 


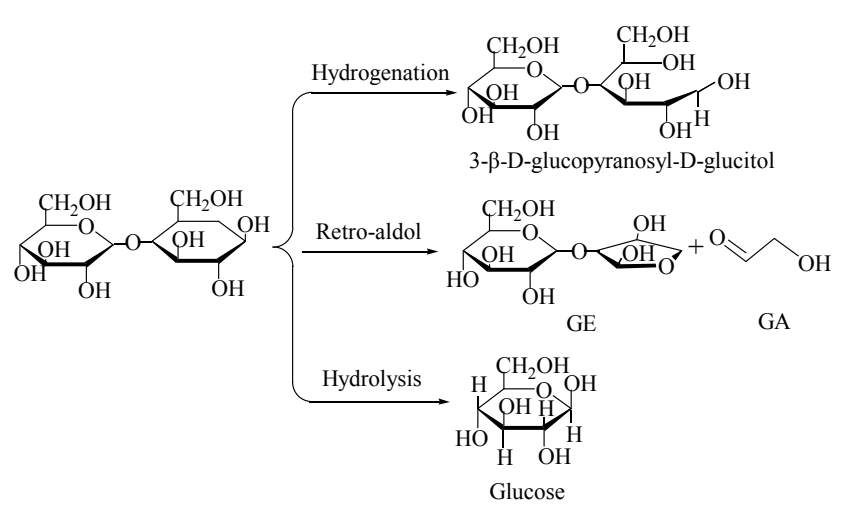

Scheme 1. Primary reaction network for cellobiose conversion catalyzed by $\mathrm{H}_{2} \mathrm{WO}_{4}$ and $\mathrm{Ru} / \mathrm{C}$.

cose would not be the only intermediate sugar during cellulose conversion to EG: other soluble celloligosaccharides derived from the partial hydrolysis of cellulose can also undergo $\mathrm{C}-\mathrm{C}$ bond cleavage to form GA. Therefore, from the product distribution, we propose the reaction pathway illustrated in Schemes 1-4. The primary reactions (Scheme 1) are three parallel reactions occurring simultaneously: (1) hydrolysis of cellobiose to form two molecules of glucose, (2) retro-aldol condensation of cellobiose to form equal-molar GE and GA, and (3) hydrogenation of cellobiose to 3- $\beta$-D-glucopyranosyl-D-glucitol. Then, the products from the primary reactions undergo secondary reactions. In the secondary reactions, glucose, GE, and 3 - $\beta$-D-glucopyranosyl-D-glucitol further undergo the several parallel and consecutive reactions shown in Schemes 2-4. Clearly, even with the simplest unit of cellulose containing only one $\beta$-1,4-glycosidic bond, the reaction network is rather complex, so this will pose a significant challenge for selectivity control for desired products.

On the other hand, from comparing the structure of cellobiose, GE and glycosyl-glycolaldehyde (GG), one can clearly see that the accessibility to the $\beta$-1,4-glycosidic bond follows the order GG > GE > cellobiose, which suggested that the retro-aldol condensation of aldose at the reducing end will further promote the hydrolysis of the $\beta$-1,4-glycosidic bond. The DFT calculation of the Gibbs free energies for the hydrolysis of these three aldoses confirmed our expectation, as shown in Table 1.

\subsection{Comparison of glucose and cellobiose transformation}

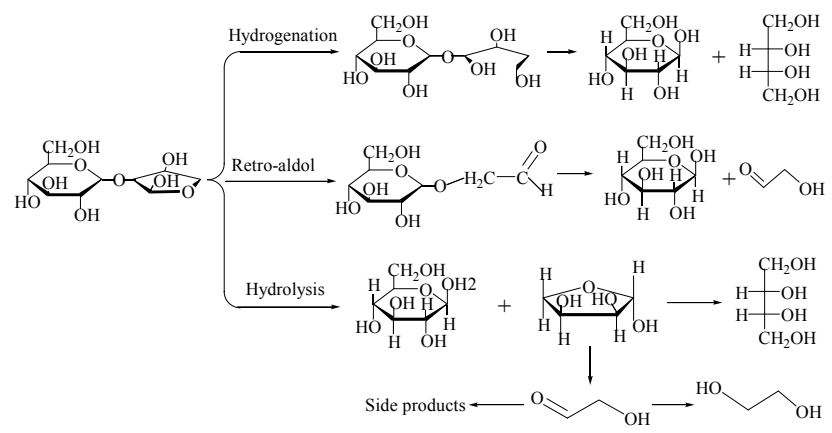

Scheme 2. Reaction network of glucosyl-erythrose catalyzed by $\mathrm{H}_{2} \mathrm{WO}_{4}$ and $\mathrm{Ru} / \mathrm{C}$.

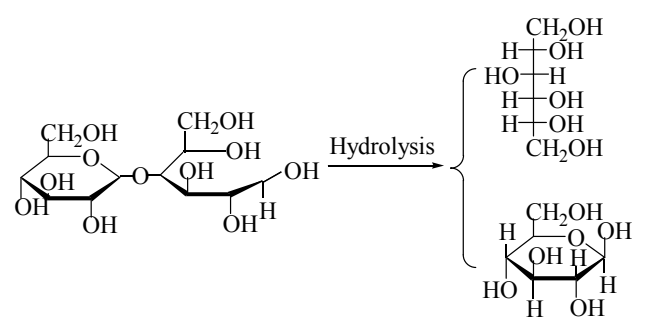

Scheme 3. Reaction network of 3- $\beta$-D-glucopyranosyl-D-glucitol catalyzed by $\mathrm{H}_{2} \mathrm{WO}_{4}$ and $\mathrm{Ru} / \mathrm{C}$.

Glucose is the basic unit of cellulose and it is formed as an intermediate in cellulose conversion to EG, while cellobiose is the smallest molecule possessing a $\beta$-1,4-glycosidic bond. Cellobiose can be considered to represent soluble celloligosaccharides that are also formed as intermediates during cellulose conversion to EG. Therefore, the comparison of glucose and cellobiose reactivity will provide mechanistic information for the cellulose conversion to EG. First, we conducted reactions at a relatively low temperature $(393 \mathrm{~K})$ for $2 \mathrm{~h}$ with a dual component catalyst of $\mathrm{H}_{2} \mathrm{WO}_{4}$ and $1 \% \mathrm{Ru} / \mathrm{C}$. As shown in Table 2, both the conversion and product distribution were different when the feedstock was changed from glucose to cellobiose. At this low temperature, the cellobiose conversion was only $6.0 \%$ while the glucose conversion reached $11.1 \%$, indicating that the intrinsic reactivity of cellobiose was low due to the presence of the $\beta$-1,4-glycosidic bond. In the case of cellobiose, 3 - $\beta$-D-glucopyranosyl-D-glucitol was the major product resulting from the direct hydrogenation of cellobiose. The production of a very small amount of sorbitol $(0.16 \%)$ suggested that hydrogenation predominated over the hydrolysis of cellobiose at temperatures lower than 393 K. Similarly, hydrogenation also occurred with glucose to produce sorbitol (9.74\%) and mannitol $(0.08 \%)$. No C-C bond cleavage took place at 393 K. Ac-

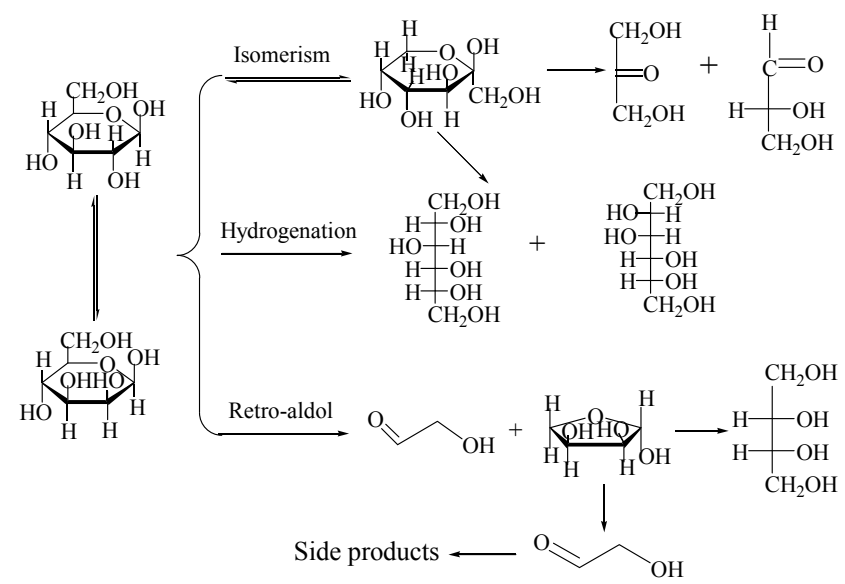

Scheme 4. Reaction network of glucose catalyzed by $\mathrm{H}_{2} \mathrm{WO}_{4}$ and $\mathrm{Ru} / \mathrm{C}$.

Table 1

Gibbs free energy for the hydrolysis of cellobiose, glucosyl-erythrose (GE), and glycosyl-glycolaldehyde (GG).

\begin{tabular}{lc}
\hline Reaction & $\Delta G(\mathrm{kcal} / \mathrm{mol})$ \\
\hline Cellobiose $+\mathrm{H}_{2} \mathrm{O} \rightarrow 2 \mathrm{Glucose}$ & 5.276 \\
$\mathrm{GE}+\mathrm{H}_{2} \mathrm{O} \rightarrow$ Glucose + Erythrose & -0.805 \\
$\mathrm{GG}+\mathrm{H}_{2} \mathrm{O} \rightarrow$ Glucose $+\mathrm{GA}$ & -0.981 \\
\hline
\end{tabular}


cording to our kinetic studies [45,46], C-C bond cleavage of glucose requires an activation energy of $141.3 \mathrm{~kJ} / \mathrm{mol}$ while the hydrogenation reaction has a much lower barrier $(49.6 \mathrm{~kJ} / \mathrm{mol})$. It should also be pointed out that the presence of $\mathrm{H}_{2} \mathrm{WO}_{4}$ in the reaction system suppressed the hydrogenation of both cellobiose and glucose leading to their low conversion even after $2 \mathrm{~h}$ for the reaction at $393 \mathrm{~K}$.

Subsequently, we investigated the reactivities of cellobiose and glucose at higher temperatures from 418 to $513 \mathrm{~K}$. Fig. 2 illustrates the product distributions from cellobiose conversion at four different temperatures. When the reaction of cellobiose proceeded at $418 \mathrm{~K}$, the main products in the initial $240 \mathrm{~min}$ were 3- $\beta$-D-glucopyranosyl-D-glucitol and glucose, while the other two minor products were sorbitol and EG, indicating that the direct hydrogenation and hydrolysis of cellobiose dominated although the $\mathrm{C}-\mathrm{C}$ bond cleavage reaction had occurred to a small extent at this temperature. However, with increasing reaction time, both sorbitol and EG increased in their yields at the expense of both 3- $\beta$-D-glucopyranosyl-D-glucitol and glucose. When the cellobiose was converted completely at $840 \mathrm{~min}$, the 3- $\beta$-D-glucopyranosyl-D-glucitol amount was almost negligible while the sorbitol and EG yields were $42.8 \%$ and $21.7 \%$, respectively. The sorbitol came from the hydrolysis of cellobiose as well as of 3- $\beta$-D-glucopyranosyl-D-glucitol followed by the hydrogenation of glucose, while the EG resulted from the retro-aldol condensation of both cellobiose and glucose followed by the hydrogenation of glycolaldehyde, as shown in Schemes 1 to 4.

When the cellobiose reaction was performed at higher temperatures (433-473 $\mathrm{K}$ ), the reaction rate was remarkably enhanced. For example, cellobiose was completely converted for 360,50 , and $15 \mathrm{~min}$ at the reaction temperature of 433, 453, and $473 \mathrm{~K}$, respectively. At the same time, the product distribution changed with increasing temperature. EG rather than sorbitol became the main product at $T \geq 433 \mathrm{~K}$, indicating the $\mathrm{C}-\mathrm{C}$ bond cleavage reaction prevailed over hydrogenation at higher temperatures. Nevertheless, in the beginning period of the reaction, one can still observe the formation of 3- $\beta$-D-glucopyranosyl-D-glucitol and glucose, and the latter became more dominant with increasing temperature, suggesting that the hydrolysis of cellobiose was more promoted at an increased temperature. It is also interesting to notice that GA appeared in the products of the cellobiose reaction at 453 and $473 \mathrm{~K}$. In previous studies of cellulose conversion [24-31], GA was always rapidly hydrogenated to EG upon its formation. In contrast, GA was not instantly hydrogenated into EG in the present cellobiose reaction, which gave the decreased EG yield. The

Table 2

Reactivity of cellobiose and glucose catalyzed by $\mathrm{H}_{2} \mathrm{WO}_{4}$ and $1 \% \mathrm{Ru} / \mathrm{C}$.

\begin{tabular}{|c|c|c|c|c|c|c|}
\hline \multirow{2}{*}{ Reactant } & \multirow{2}{*}{ Conversion (\%) } & \multicolumn{5}{|c|}{ Yield (\%) } \\
\hline & & 3- $\beta$-D-glucopyranosyl-D-glucitol & Sorbitol & Mannitol & EG & 1,2-PG \\
\hline Cellobiose & 6.0 & 4.83 & 0.16 & 0 & 0 & 0 \\
\hline Glucose & 11.1 & 0 & 9.74 & 0.08 & 0 & 0 \\
\hline
\end{tabular}

Reaction conditions: $0.1 \mathrm{~g} \mathrm{H}_{2} \mathrm{WO}_{4}, 0.3 \mathrm{~g}$ 1\%Ru/C, $6 \mathrm{MPa} \mathrm{H}, 1000 \mathrm{r} / \mathrm{min}, 393 \mathrm{~K}, 2 \mathrm{~h}$.
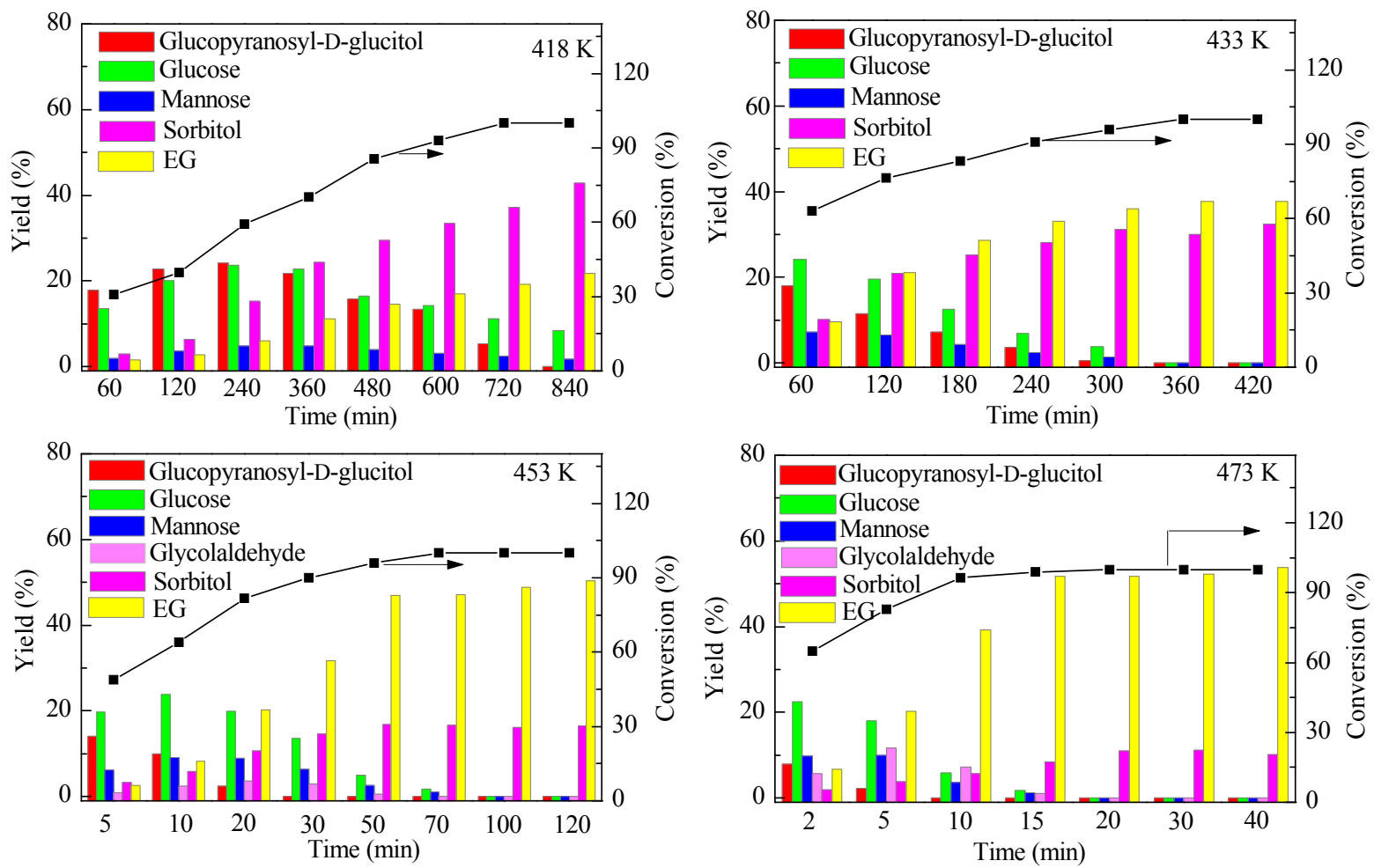

Fig. 2. Product distribution versus time for cellobiose conversion at different temperatures. Reaction conditions: $0.10 \mathrm{~g} \mathrm{H}_{2} \mathrm{WO}_{4}, 0.30 \mathrm{~g} \mathrm{Ru} / \mathrm{AC}, 6 \mathrm{MPa}$ $\mathrm{H}_{2}, 1000 \mathrm{r} / \mathrm{min}$. 
underlying reason may lie in that the retro-aldol condensation rate of cellobiose and its derived glucose is much higher than that of cellulose, which led to the production of excess GA. Since GA hydrogenation involves heterogeneous catalysis over $\mathrm{Ru}$, the gas-liquid and liquid-solid mass transfer rate may lower the apparent hydrogenation rate although the activation energy of GA hydrogenation was only $42.6 \mathrm{~kJ} / \mathrm{mol}$. Increasing the $\mathrm{Ru} / \mathrm{C}$ catalyst amount or by removing the possible mass transfer limitation is an effective way to accelerate GA hydrogenation and increasing the EG yield.

Fig. 3 presents the glucose conversion at different tempera-
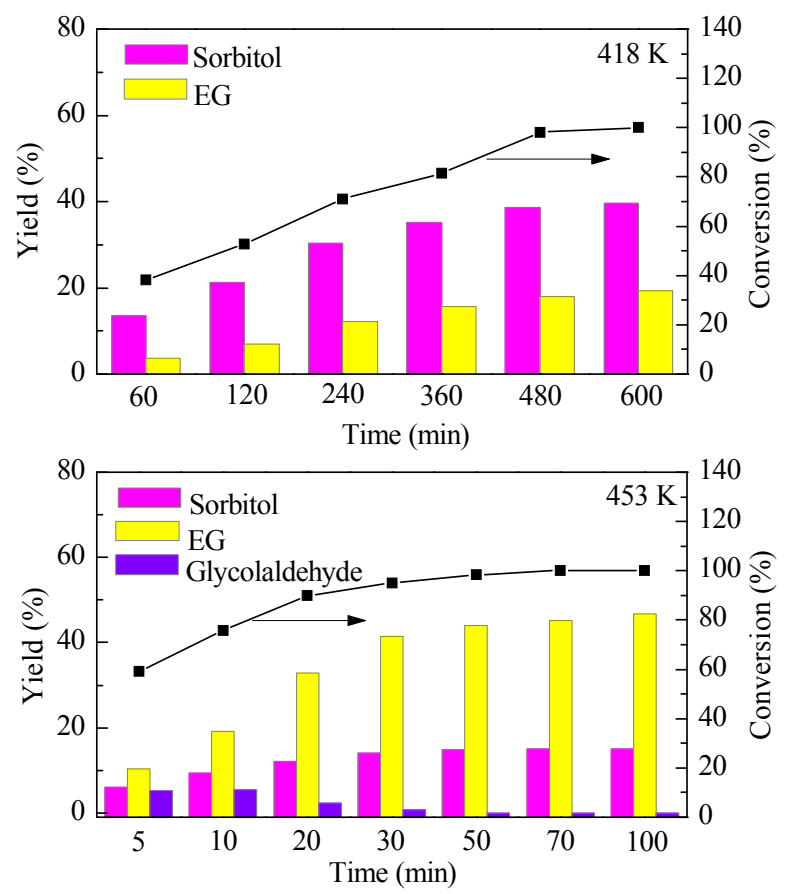

tures. Similar to the cellobiose conversion, the direct hydrogenation of glucose also significantly prevailed over the $\mathrm{C}-\mathrm{C}$ bond cleavage reaction at a relatively low temperature of 418 $\mathrm{K}$, leading to the major production of sorbitol and minor production of EG. With the increase of the reaction temperature, the $\mathrm{C}-\mathrm{C}$ bond cleavage reaction of glucose gradually dominated the hydrogenation leading to the major production of EG, similar to the case of cellobiose. However, on comparing the EG yields in the glucose and cellobiose reactions at the same conditions (Fig. 4.), we can find that the former is much faster than the latter in the initial periods of the reaction, suggesting that
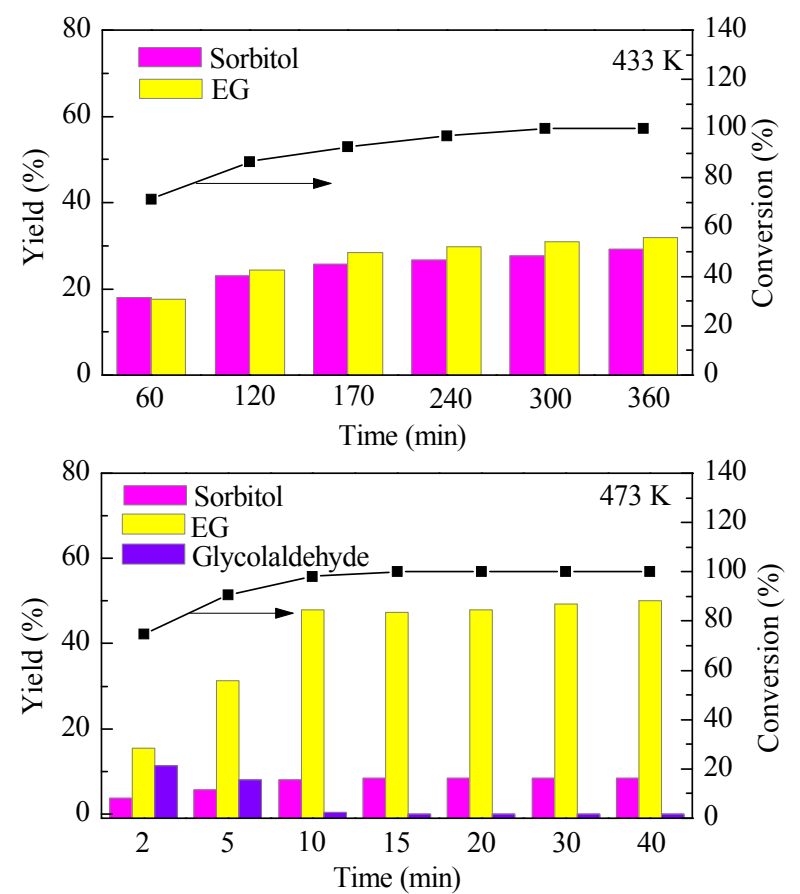

Fig. 3. Product distribution versus time for glucose conversion at different temperatures. Reaction conditions: $0.10 \mathrm{~g} \mathrm{H}_{2} \mathrm{WO}_{4}, 0.30 \mathrm{~g} \mathrm{Ru} / \mathrm{AC}, 6 \mathrm{MPa} \mathrm{H}_{2}$, $1000 \mathrm{r} / \mathrm{min}$.
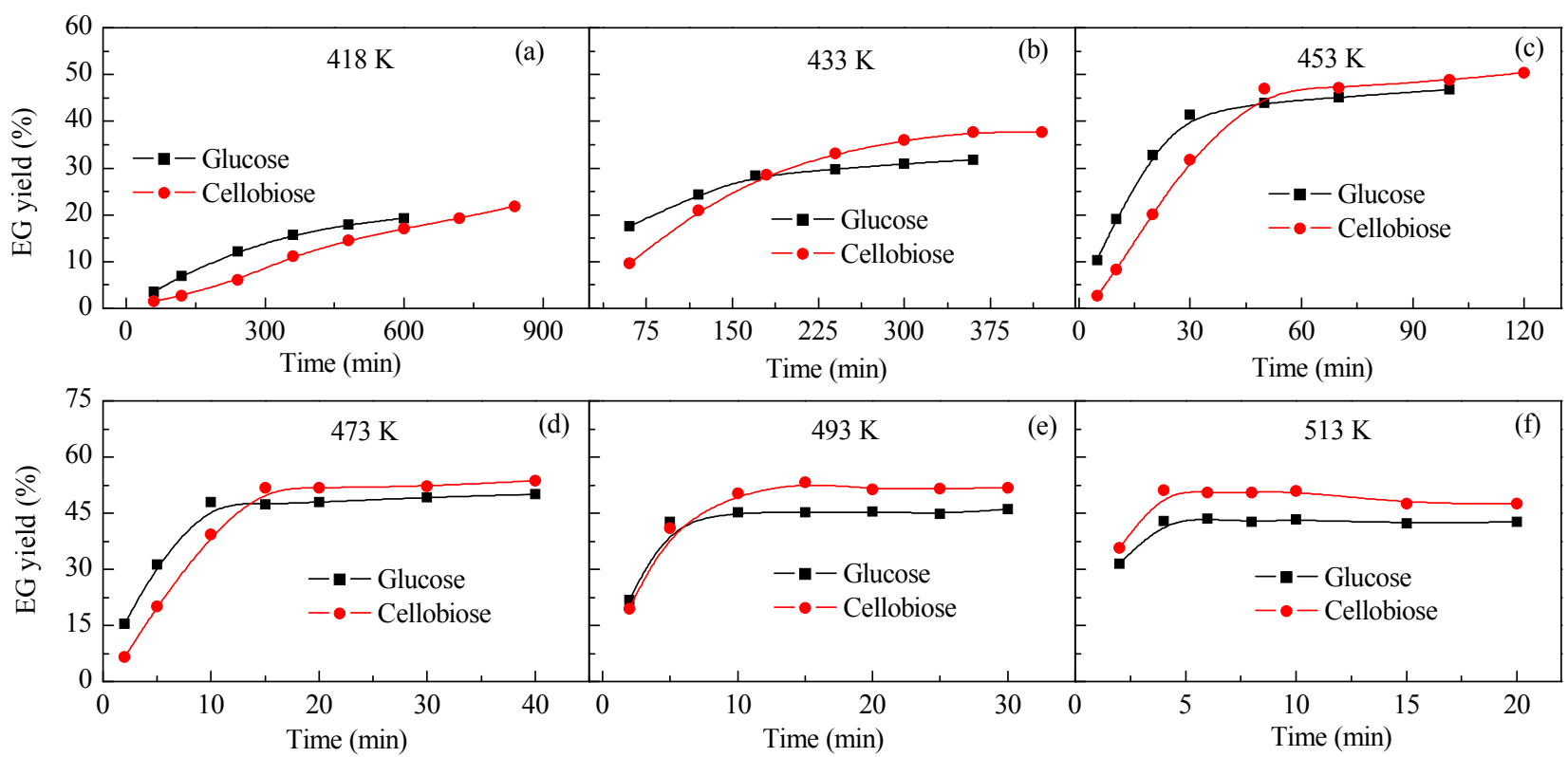

Fig. 4. Ethylene glycol yield as a function of reaction time for glucose and cellobiose conversion. Reaction conditions: $0.10 \mathrm{~g} \mathrm{H}_{2} \mathrm{WO}_{4}, 0.30 \mathrm{~g} \mathrm{Ru} / \mathrm{AC}, 6$ $\mathrm{MPa} \mathrm{H}_{2}, 1000 \mathrm{r} / \mathrm{min}$. 


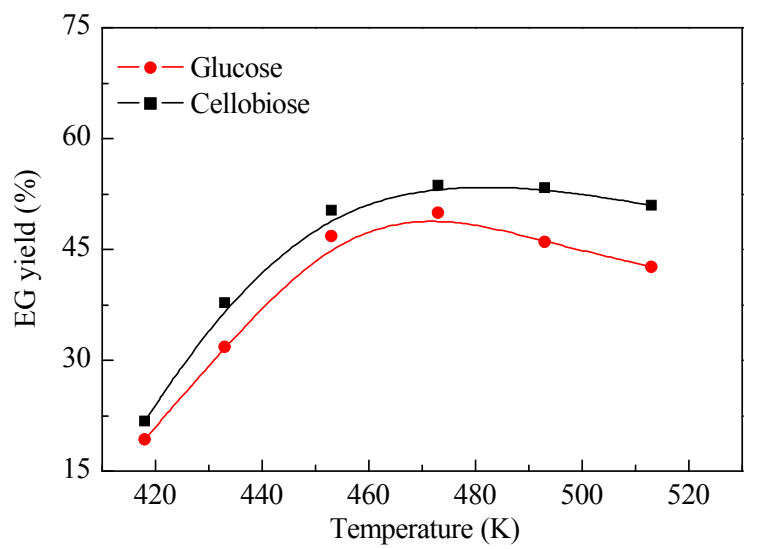

Fig. 5. Ethylene glycol yields at $100 \%$ cellobiose or glucose conversion as a function of temperature. Reaction conditions: $0.10 \mathrm{~g} \mathrm{H}_{2} \mathrm{WO}_{4}, 0.30 \mathrm{~g}$ $\mathrm{Ru} / \mathrm{AC}, 6 \mathrm{MPa} \mathrm{H}_{2}$, stirring speed $1000 \mathrm{r} / \mathrm{min}$.

the $\mathrm{C}-\mathrm{C}$ bond cleavage reaction of glucose is much easier than that of cellobiose. Nevertheless, with the increasing of reaction time, the EG yield from cellobiose conversion surpassesed that from glucose. Moreover, with an increase of the reaction temperature, the intersecting point of the EG yields of glucose and cellobiose shifted to a shorter reaction time (Fig. 4(b)-(f)), suggesting that a higher temperature is more favorable for the retro-aldol condensation of cellobiose in comparison with that of glucose. At each temperature, the final EG yield at $100 \%$ conversion of cellobiose was always higher than that of glucose, and the difference became larger at higher temperature (Fig. 5.). This can be explained by the slow retro-aldol condensation of cellobiose as well as slow release of glucose from the hydrolysis of cellobiose, which is better matched with the subsequent hydrogenation of GA. On extrapolating this to cellulose conversion, this trend would hold if the hydrolysis of cellulose is much more difficult than cellobiose and the resulting glucose concentration in the solution is much lower, i.e., the EG yield would follow the order of cellulose > celloligosaccharides > glucose. However, this trend can be changed by tuning the ratio of $\mathrm{H}_{2} \mathrm{WO}_{4}$ to $\mathrm{Ru} / \mathrm{C}$ as well as by optimizing the reaction conditions [34].

\section{Conclusions}

From an investigation of the hydrogenolysis of cellobiose to EG, we elucidated the reaction pathways in which hydrogenation, hydrolysis and retro-aldol condensation occurred simultaneously. DFT calculations suggested that the retro-aldol condensation of aldoses at the reducing end promoted the hydrolysis of the $\beta$-1,4-glycosidic bond. The comparison of the cellobiose and glucose reactions showed that the retro-aldol condensation of cellobiose is more difficult than that of glucose, which lowered the formation rate of glycolaldehyde and made it more matched with the subsequent hydrogenation rate, thus leading to increased yield of EG from cellobiose. This trend can be extrapolated to cellulose. This study provided useful information for the mechanistic understanding of cellulose conversion to EG and will guide the design of more efficient and selective catalyst formulations.

\section{References}

[1] Alonso D M, Bond J Q, Dumesic J A. Green Chem, 2010, 12: 1493

[2] Huber G W, Iborra S, Corma A. Chem Rev, 2006, 106: 4044

[3] Corma A, Iborra S, Velty A. Chem Rev, 2007, 107: 2411

[4] Dhepe P L, Fukuoka A. ChemSusChem, 2008, 1: 969

[5] Yu Y, Lou X, Wu H W. Energy Fuels, 2008, 22: 46

[6] Stöcker M. Angew Chem Int Ed, 2008, 47: 9200

[7] Rinaldi R, Schüth F. Energy Environ Sci, 2009, 2: 610

[8] Zhou C H, Xia X, Lin C X, Tong D S, Beltramini J. Chem Soc Rev, 2011, 40: 5588

[9] Kobayashi H, Komanoya T, Guha S K, Hara K, Fukuoka A. Appl Catal A, 2011, 409-410: 13

[10] Gallezot P. Chem Soc Rev, 2012, 41: 1538

[11] Wang Y L, Deng W P, Wang B J, Zhang Q H, Wan X Y, Tang Z C, Wang Y, Zhu C, Cao Z X, Wang G C, Wan H L. Nat Commun, 2013, 4: 2141

[12] Ma J P, Yu W Q Wang M, Jia X Q, Lu F, Xu J. Chin J Catal (马继平, 于 维强, 王敏, 贾秀全, 路芳, 徐杰. 催化学报), 2013, 34: 492

[13] Zhao C, Kou Y, Lemonidou A A, Li X B, Lercher J A. Angew Chem Int $E d, 2009,48: 3987$

[14] Alonso D M, Bond J Q, Dumesic J A. Green Chem, 2010, 12: 1493

[15] Peng B X, Yuan X G, Zhao C, Lercher J A. J Am Chem Soc, 2012, 134: 9400

[16] Li G Y, Li N, Li S S, Wang A Q Cong Y, Wang X D, Zhang T. Chem Commun, 2013, 49: 5727

[17] Yang J F, Li N, Li G Y, Wang W T, Wang A Q Wang X D, Cong Y, Zhang T. ChemSusChem, 2013, 6: 1149

[18] Wang S, Liu H C. Chin J Catal (王帅, 刘海超. 催化学报), 2014, 35: 631

[19] Zhang X C, Wang M, Wang Y H, Zhang C F, Zhang Z, Wang F, Xu J. Chin J Catal (张晓辰, 王敏, 王业红, 张超峰, 张哲, 王峰, 徐杰. 催化 学报), 2014, 35: 703

[20] Dong X L, Xue S, Zhang J L, Huang W, Zhou J N, Chen Z A, Yuan D H, Xu Y P, Liu Z M. Chin J Catal (董兴隆, 薛松, 张今令, 黄为, 周建男, 陈兆安, 袁丹华, 徐云鹏, 刘中民. 催化学报), 2014, 35: 684

[21] Xiao Z H, Jin S H, Pang M, Liang C H. Green Chem, 2013, 15: 891

[22] Komanoya T, Kobayashi H, Hara K, Chun W J, Fukuoka A. ChemCatChem, 2014, 6: 230

[23] Ji N, Zhang T, Zheng M Y, Wang A Q, Wang H, Wang X D, Chen J G. Angew Chem Int Ed, 2008, 47: 8510

[24] Zhang Y H, Wang A Q Zhang T. Chem Commun, 2010, 46: 862

[25] Zheng M Y, Wang A Q, Ji N, Pang J F, Wang X D, Zhan T. ChemSusChem, 2010, 3: 63

[26] Zhao G H, Zheng M Y, Wang A Q, Zhang T. Chin J Catal (赵冠鸿, 郑 明远, 王爱琴, 张涛. 催化学报), 2010, 31: 928

[27] Pang J F, Zheng M Y, Wang A Q Zhang T. Ind Eng Chem Res, 2011, 50: 6601

[28] Li C Z, Zheng M Y, Wang A Q, Zhang T. Energy Environ Sci, 2012, 5: 6383

[29] Ji N, Zheng M Y, Wang A Q, Zhang T, Chen J G. ChemSusChem, 2012, 5: 939

[30] Tai Z J, Zhang J Y, Wang A Q, Zheng M Y, Zhang T. Chem Commun, 2012, 48: 7052

[31] Tai Z J, Zhang J Y, Wang A Q, Pang J F, Zheng M Y, Zhang T. ChemSusChem, 2013, 6: 652

[32] Wang A Q, Zhang T. Acc Chem Res, 2013, 46: 1377

[33] Zhou L K, Pang J F, Wang A Q Zhang T. Chin J Catal (周立坤, 庞纪 峰, 王爱琴, 张涛. 催化学报), 2013, 34: 2041

[34] Zhao G H, Zheng M Y, Zhang J Y, Wang A Q, Zhang T. Ind Eng Chem Res, 2013, 52: 9566

[35] Zheng M Y, Pang J F, Wang A Q Zhang T. Chin J Catal (郑明远, 庞纪 


\section{Graphical Abstract}

Chin. J. Catal, 2014, 35: 1811-1817 doi: 10.1016/S1872-2067(14)60151-0

\section{Comparison of cellobiose and glucose transformation to ethylene glycol}

Junying Zhang, Xiaofeng Yang, Baolin Hou, Aiqin Wang*, Zhenlei Li, Hua Wang, Tao Zhang* Dalian Institute of Chemical Physics, Chinese Academy of Sciences; University of Chinese Academy of Sciences

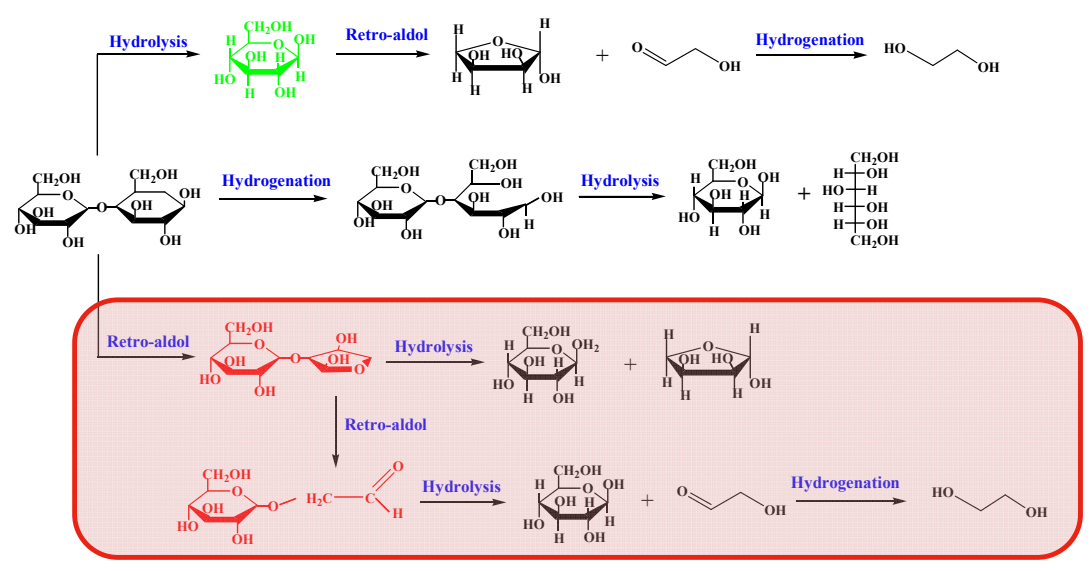

A new reaction pathway was proposed for cellobiose conversion. The retro-aldol condensation of cellobiose is more difficult than that of glucose, leading to increased yield of EG from cellobiose.

峰, 王爱琴, 张涛. 催化学报), 2014, 35: 602

[36] Liu Y, Luo C, Liu H C. Angew Chem Int Ed, 2012, 51: 3249

[37] Huang Y B, Fu Y. Green Chem, 2013, 15: 1095

[38] Song J L, Fan H L, Ma J, Han B X. Green Chem, 2013, 15: 2619

[39] Kabyemela B M, Takigawa M, Adschiri T, Malaluan R M, Arai K. Ind Eng Chem Res, 1998, 37: 357

[40] Sasaki M, Furukawa M, Minami K, Adschiri T, Arai K. Ind Eng Chem Res, 2002, 41: 6642

[41] Yan N, Zhao C, Luo C, Dyson P J, Liu H C, Kou Y. J Am Chem Soc,
2006, 128: 8714

[42] Deng W P, Liu M, Tan X S, Zhang Q H, Wang Y. J Catal, 2010, 271: 22

[43] Delley B. J Chem Phys, 1990, 92: 508

[44] Delley B.J Chem Phys, 2000, 113: 7756

[45] Zhang J Y, Hou B L, Wang A Q, Li Z L, Wang H, Zhang T. AIChE J, 2014, DOI: 10.1002/aic.14554

[46] Zhang J Y, Hou B L, Wang A Q, Li Z L, Wang H, Zhang T. AIChE J, in Press

\section{纤维二糖与葡萄糖催化转化制备乙二醇}

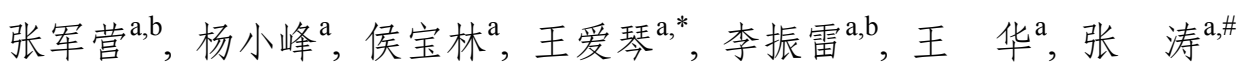

a中国科学院大连化学物理研究所催化基础国家重点实验室, 辽宁大连 116023

中国科学院大学, 北京100049

摘要: 选用纤维二糖作为探针分子, 探索纤维素催化转化制备乙二醇过程的反应路径. 分别考察了纤维二糖和葡萄糖在双组分催 化剂 $\mathrm{H}_{2} \mathrm{WO}_{4}$ 和 $\mathrm{Ru} / \mathrm{C}$ 下的催化反应活性. 结果表明, 乙二醇不仅来自于纤维二糖水解产物葡萄糖的逆羟醛缩合作用, 同时也可以来 自于纤维二糖的直接逆羟醛缩合过程. 而且, 纤维二糖的直接逆羟醛缩合作用对糖苷键的水解也有一定的促进作用. 比较发现, 铇基催化剂作用下纤维二糖的逆差醛缩合反应活性比葡萄糖要低, 因此乙醇醛可以缓慢产生并在 $\mathrm{Ru} / \mathrm{C}$ 催化剂上迅速加氢生成乙 二醇. 使得以纤维二糖作为原料比以葡萄糖作为原料时获得更高的乙二醇收率.

关键词: 纤维二糖; 反应机理；葡萄糖；乙二醇

收稿日期: 2014-04-29. 接受日期: 2014-05-10. 出版日期: 2014-11-20.

*通讯联系人. 电话: (0411)84379348; 传真: (0411)84685940; 电子信箱: aqwang@dicp.ac.cn

通讯联系人. 电话: (0411)84379015; 传真: (0411)84691570; 电子信箱: taozhang@dicp.ac.cn

基金来源: 国家自然科学基金(21176235, 21373206, 21206159).

本文的英文电子版由Elsevier出版社在ScienceDirect上出版(http://www.sciencedirect.com/science/journal/18722067). 